\title{
SELECTIVE SYNTHESIS OF PEG-MONOESTER USING CESIUM HETEROPOLY ACID AS HETEROGENEOUS CATALYST
}

\author{
Fatimah Zahara Abdullah"*, Azman Ma'amor ${ }^{\mathrm{b}}$, Nur Atiqah Daud ${ }^{\mathrm{a}}$ and Sharifah Bee Abd Hamid \\ ${ }^{a}$ Nanotechnology and Catalysis Research Centre, University of Malaya, 50603 Kuala Lumpur, Malaysia \\ ${ }^{b}$ Department of Chemistry, Faculty of Science, University of Malaya, 50603 Kuala Lumpur, Malaysia
}

Recebido em 15/08/2016; aceito em 01/02/2017; publicado na web em 05/04/2017

\begin{abstract}
Esterification of oleic acid with polyethylene glycol 600 (PEG-600) to produce polyethylene glycol monooleate (PEG-monooleate) and polyethylene glycol dioleate (PEG-dioleate) as by-product has been studied in the presence of heterogeneous acid catalysts, i.e. cesium heteropoly acid (Cs HPA). The results are compared with those obtained from a classical homogeneous acid catalyst; $p$-toluene sulphonic acid ( $p$-TSA). The reaction was conducted under nitrogen flow with vigorous stirring at $130{ }^{\circ} \mathrm{C}$ and $150{ }^{\circ} \mathrm{C}$. The catalyst loading kept at $4 \%$ and the reaction was monitored at 1, 3, 7 and 24 hours. Reaction samples were analyzed using high performance liquid chromatography (HPLC) equipped with evaporative light scattering detector (ELSD). The results obtained showed that Cs HPAs exhibit $100 \%$ selectivity of PEG-monooleate from the first hour until 24 hours. However, this does not happen with homogeneous $p$-TSA, where formation of by-product; PEG-dioleate is observed in the initial stage. It is also showed that the mole ratio is the most important parameter not only to produce high yield of monoester but also to maintain it along the reaction. Chemical and physical properties of catalysts were characterized using Thermal Gravimetric Analysis (TGA), Differential Scanning Calorimetry (DSC), Fourier Tranmittance Infra-Red (FTIR), ammonia temperature programmed desorption ( $\left.\mathrm{NH}_{3}-\mathrm{TPD}\right)$ and X-ray Diffraction (XRD).
\end{abstract}

Keywords: esterification; oleic acid; polyethylene glycol 600; PEG-monooleate; cesium heteropoly acid (Cs HPA).

\section{INTRODUCTION}

Polyethylene glycol monooleate (PEG-monooleate) is synthesized via esterification of oleic acid and polyethylene glycol 600 (PEG-600). Known for its low toxicity, application of this nonionic surfactant covers in many daily usage products such as in food, pharmaceutical, cosmetics, lubricants, etc. ${ }^{1,2}$ This compound has good solubility and viscosity properties, making it good as emulsifiers, humectants, binders, stabilizer, viscosity controlling agent and emollients. ${ }^{3}$ Among reported catalysts used in this reaction are homogeneous catalysts such as mineral acids; $\mathrm{H}_{2} \mathrm{SO}_{4} \mathrm{HI}, \mathrm{HF}, \mathrm{H}_{3} \mathrm{PO}_{4}, p$-TSA and $\mathrm{HCOOH} .^{4-7}$ These homogenous catalytic systems have limitations due to: 1) difficulties in recovering the catalysts after reaction completed, and 2) product purification. In addition, homogeneous catalysts generates huge amount of wastewater, and can be corrosive that lead to corrosion on reactor and pipelines besides being energy intensive and high cost. ${ }^{8,9}$ Heterogeneous catalysts are much preferred catalysts since the reaction can occur under mild reaction condition, less energy intensive, easy separation of catalyst from product, high possibility to regenerate and reuse the catalyst. ${ }^{9}$ Example of heterogeneous catalysts reported are $\mathrm{ZrO}_{2}, \mathrm{TiO}_{2}, \mathrm{SnO}_{2}$, sulfonic ion-exchange resin, sulfonic modified mesostructure $\mathrm{SiO}_{2}$, sulfonated carbon-based catalyst, heteropolyacids (HPAs), aluminosilicates (mordenite, halloysite, kaolinite) and cation-exchange resins. ${ }^{7}$ Another approach for this reaction is using enzyme which is even better than heterogeneous catalyst in terms of environmental friendly. ${ }^{10-12}$ Despite the many advantages in enzymatic catalyzed reactions, there are also some drawbacks making it difficult to be applied in industry such as the high cost of enzymes, slow reaction rate and fast enzymes deactivation. ${ }^{8,13}$

Esterification product is normally a mixture of monoesters and diesters. The formation of the PEG monoester is the first step in esterification (Figure 1). Fatty acid diesters is formed since PEG has two hydroxyl groups available to react with the carboxylic acid. The

*e-mail: fatimahzahara@um.edu.my esterification of PEG with fatty acids is reversible and consequently the reaction cannot achieve completion. As the conversion approaches completion, the equilibrium can be shifted by removing one of the products, such as water since water molecules can hydrolyse the product to revert back to fatty acids and alcohol. Normally, water from reaction mixture is removed by vacuum or by a current of air or inert gas.

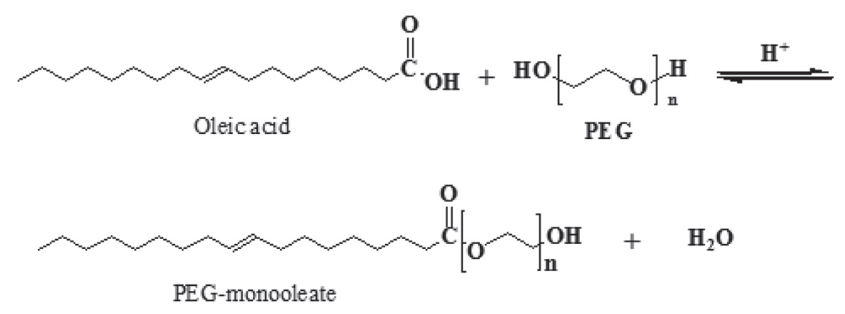<smiles>CCCCCCCCCCCCCC(=O)OCCOC(=O)CCCCCCCCCCCC</smiles>

Figure 1. Esterification of oleic acic and PEG

The relative content of monoesters and diester in the equilibrium mixture depends on the ratio of the reactants. Higher molar ratio of fatty acid to PEG favors greater concentration of diester in the mixture. In the preparation of monoesters, an excess of PEG is usually used to react with fatty acid to assure its high conversion.

In strong Bronsted acid catalyst, cesium heteropoly acid (Cs HPA) was used to catalyzed the esterification of oleic acid and PEG-600. As our knowledge, there is no Cs HPA catalyzed esterification of oleic acid 
and PEG-600 is reported to date. There are very few articles reporting esterification using PEG-600 as reactant since it is a bulky compound. Catalytic performance was studied under several parameters such as the effect of mole ratio, reaction temperature, reaction time and acidity of catalyst. Results obtained are compared with homogeneous acid catalyst $p$-TSA interm of conversion of oleic acid as well as selectivity and yield of PEG-monooleate. It is important to choose the right catalyst for this esterification. Therefore, the objective of this study is the application of strong solid catalyst (heterogeneous) compared to conventional liquid catalyst (homogeneous).

\section{EXPERIMENTAL}

\section{Materials}

Oleic acid, technical grade (90\%, Aldrich), polyoxyethylene of molecular weight 600 (PEG-600) (Aldrich) were used for the reaction studies. The experiments were conducted under reflux in a standarddesign glass apparatus where the temperature is regulated with silicon oil bath equipped with a temperature controller.

\section{Syntheses of $\mathrm{Cs}_{2.5} \mathrm{H}_{0.5} \mathrm{PW}_{12} \mathrm{O}_{40}$ and $\mathrm{Cs}_{1.87} \mathrm{H}_{1.13} \mathrm{PW}_{12} \mathrm{O}_{40}$}

Cs HPAs were synthesized as reported and undergone activation prior to reaction under vacuum at $100^{\circ} \mathrm{C}$ for 2 hours. ${ }^{14}$ The $0.08 \mathrm{M} \mathrm{H}_{3} \mathrm{PW}_{12} \mathrm{O}_{40}$ aqueous solution was prepared by dissolving $18.0 \mathrm{~g}$ of $\mathrm{H}_{3} \mathrm{PW}_{12} \mathrm{O}_{40}$ salt ( 0.00625 moles) in $80 \mathrm{~mL}$ of deionized water. To the aqueous solution of $\mathrm{H}_{3} \mathrm{PW}_{12} \mathrm{O}_{40}$ was added with $0.25 \mathrm{M} \mathrm{Cs}_{2} \mathrm{CO}_{3}$ aqueous solution which was prepared by dissolving $2.54 \mathrm{~g}$ of $\mathrm{Cs}_{2} \mathrm{CO}_{3}$ salt in $32 \mathrm{~mL}$ of deionized water. The $\mathrm{Cs}_{2} \mathrm{CO}_{3}$ aqueous solution was added dropwise $\left(1 \mathrm{~mL} \mathrm{~min}{ }^{-1}\right)$ to the aqueous solution of $\mathrm{H}_{3} \mathrm{PW}_{12} \mathrm{O}_{40}$ at ambient temperature with vigorous stirring by using a magnetic bar. From the onset of the addition of $\mathrm{Cs}_{2} \mathrm{CO}_{3}$ aqueous solution, fine particles were formed to make the solution milky. The precipitation was allowed to stand for 1 hour at room temperature. The water was then slowly removed by evaporation at $80^{\circ} \mathrm{C}$ and the resultant solid was grinded into white powder by using ceramic mortal and pestle.

The same method was applied to prepare $\mathrm{Cs}_{1.87} \mathrm{H}_{1.13} \mathrm{PW}_{12} \mathrm{O}_{40}$ but respective amounts of $\mathrm{H}_{3} \mathrm{PW}_{12} \mathrm{O}_{40}$ and $\mathrm{Cs}_{2} \mathrm{CO}_{3}$ were changed, i.e., by dissolving $18.43 \mathrm{~g}$ of $\mathrm{H}_{3} \mathrm{PW}_{12} \mathrm{O}_{40}(0.0064$ mole, $0.08 \mathrm{M})$ in $80 \mathrm{~mL}$ of deionized water and $1.95 \mathrm{~g}_{\text {of }} \mathrm{Cs}_{2} \mathrm{CO}_{3}(0.00598$ mole, $0.25 \mathrm{M})$ in $24 \mathrm{~mL}$ of deionized water.

\section{Catalyst characterization}

X-ray diffraction (XRD) measurements were carried out using Bruker D8 Advance Powder X-ray diffractometer $(\theta-2 \theta$ mode, $\mathrm{Cu}-\mathrm{Ka}$ radiation at $\mathrm{l}=1.5405 \mathrm{~A}$, scintillation detector) equipped with EVA diffract software for data acquisition and analysis. The diffractogram were recorded over $2 \theta$ values ranging from $2-60^{\circ}$ with a scanning rate of $0.04 \mathrm{~s} / \mathrm{step}$ at ambient temperature. The crystal phases of the sample were identified by overlaying the standard JCPDS diffraction pattern matching both peak positions and relative intensity. Both, -OH groups and acidity, were monitored by infrared spectroscopy. FT-IR spectra were recorded in the transmission mode using Bruker IFS66V/S spectrometer. Thermal stability information was obtained from Thermogravimetric Analysis (TGA) using Mettler Toledo TGA/SDTA851 ${ }^{\mathrm{e}}$ and Differential Scanning Calorimetry (DSC) using Mettler Toledo DSC822 .

Temperature-programmed desorption (TPD) monitors the surface or bulk processes of solid catalysts in the presence of gaseous environment. Continuously, the gas phase composition is analyzed by thermal conductivity detector (TCD) as the temperature is raised linearly with time. The acidity of the catalysts was measured using $\mathrm{NH}_{3}$ as a probe molecule. The TPD- $\mathrm{NH}_{3}$ experiments were carried out on a Thermo Finnigan TPDRO 1100. As much as $0.1 \mathrm{~g}$ of the catalyst was activated at $600^{\circ} \mathrm{C}$ by raising the temperature at a rate of $4{ }^{\circ} \mathrm{C} \mathrm{min}{ }^{-1}$ in helium flow $\left(30 \mathrm{~mL} \mathrm{~min}^{-1}\right)$ for $1 \mathrm{~h}$. The temperature was decreased to $50{ }^{\circ} \mathrm{C}$ and $\mathrm{NH}_{3}$ was adsorbed by exposing the samples to $10 \% \mathrm{NH}_{3}$ in helium for $1 \mathrm{~h}$. It was then flushed with helium for another $1 \mathrm{~h}$ at $150{ }^{\circ} \mathrm{C}$ to remove all the physisorbed $\mathrm{NH}_{3}$. Desorption of $\mathrm{NH}_{3}$ was carried out in helium flow $\left(30 \mathrm{~mL} \mathrm{~min}^{-1}\right)$ by increasing the temperature from $150{ }^{\circ} \mathrm{C}$ to $900{ }^{\circ} \mathrm{C}$ at the rate of $10^{\circ} \mathrm{C} \mathrm{min}-1$. While desorption temperature can be related to the strength, the amount of ammonia desorbed gives an estimate of the concentration of acid sites.

\section{Reaction procedure}

Catalyst loading used for Cs HPA was kept at $4 \%$ of total mass of reactants. Meanwhile, for homogeneous catalyst; $p$-toluene sulfonic acid ( $p$-TSA), the catalyst loading used was $0.5 \%$ and was used directly without activation.

The activation was carried using three neck round bottom flask with rubber septum stopper closed two of the neck. Vacuum line was connected to the middle neck and heating mantle equipped with temperature controller was used for heating. After 2 hours, the heating was stopped and the catalyst was let to cool down to room temperature without disconnect the vacuum line.

Oleic acid $(0.283 \mathrm{~g} ; 1 \mathrm{mmol})$ was added to the activated catalyst by injecting into the flask using a syringe until the catalyst surface was well covered by the reactant. This was done to make sure no moisture reacted with the catalyst.

At this point, the vacuum was disconnected slowly and PEG-600 ( $0.621 \mathrm{~g} ; 1 \mathrm{mmol})$ was subsequently added to the reaction flask. Two different mole ratios of oleic acid to PEG-600 were used, namely 1:1 and 1:4. Esterification reaction was carried out at $130{ }^{\circ} \mathrm{C}$ under vigorous stirring in inert atmosphere condition by bubbling nitrogen gas into the reaction mixture. This also helped to remove water produced during the reaction so that the reaction equilibrium could be favorably shifted in favor of esterification reaction as opposed to hydrolysis. The progress of reaction was monitored by continuous sampling of $0.5 \mathrm{~mL}$ reaction mixture after 1, 3, 7 and 24 hours. Samples collected were centrifuged at $15,000 \mathrm{rpm}$ for 3 minutes to separate the solid catalysts from the liquid fractions. At the end of the reaction, the mixture was cooled to room temperature and filtered. Excess PEG-600 was removed by repeated washing with saturated brine solution. The same method was applied for $150{ }^{\circ} \mathrm{C}$ as the reaction temperature.

\section{Analytical procedure}

Reaction analysis was performed by using HPLC Waters 1525 system equipped with binary pump. Evaporative Light Scattering Detector (ELSD) by Eurosep was used as the detector and the column was reverse phase $C_{18}$ column $\left(C_{18}\right.$ Symmetry ${ }^{\circledR} 5 \mu \mathrm{m} 4.6$ $\mathrm{mm} \times 159 \mathrm{~mm})$. The nitrogen supply for ELSD was maintained at $0.5 \mathrm{Bar}$ and the analysis was conducted under gradient conditions of 90:10 (acetonitrile:acetone). In this analysis, stearic was used as internal standard.

\section{RESULTS AND DISCUSSION}

\section{Catalyst characterization}

Structural analysis by $\mathrm{X}$-ray diffraction

$\mathrm{Cs}_{2.5} \mathrm{H}_{0.5} \mathrm{PW}_{12} \mathrm{O}_{40}$ and $\mathrm{Cs}_{1.87} \mathrm{H}_{1.13} \mathrm{PW}_{12} \mathrm{O}_{40}$ are Keggin structure which high thermal stability. Figure 2 below shows the XRD 
diffragtogram of Cs $2.50 \mathrm{HPA}$ and Cs 1.87 HPA. When overlying the diffratograms with the standard JCPDS pattern, both of the Cs HPA catalysts shows good match and no foreign peaks is found in the diffratograms. The Cs crystallinity increases with the addition of Cs metal content in the parent acid (heteropoly acid) where Cs 2.50 HPA intensity is higher as compared to Cs $1.87 \mathrm{HPA}$ (Figure 2). This observation is in agreement with the work performed by $\mathrm{H}$. Benaissa. ${ }^{15}$

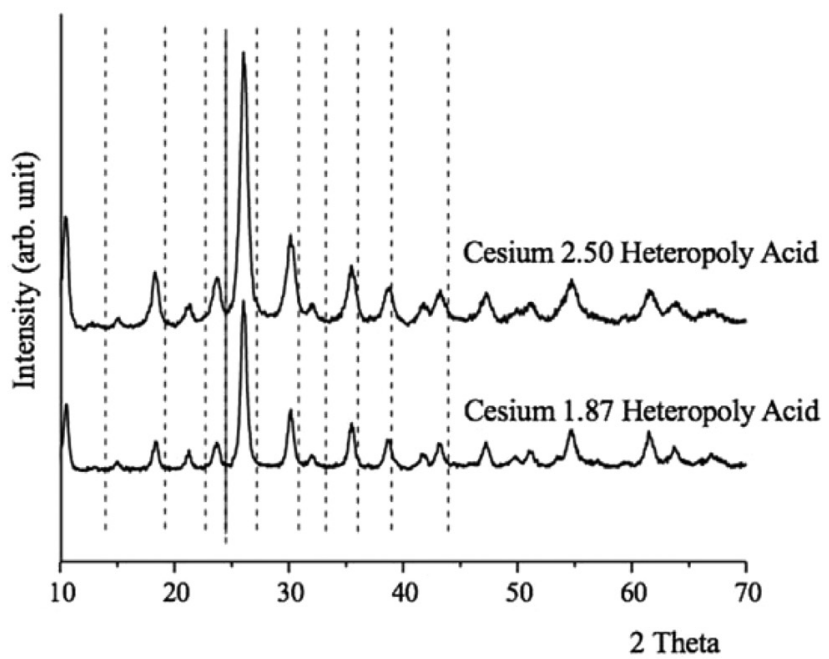

Figure 2. Phase identification of catalysts by X-ray diffraction technique (XRD)

As reported by Mizuno et al., the signal in the range of $2 \theta$ between $5^{\circ}$ to $35^{\circ}$, are assigned to cubic system. ${ }^{16}$ This finding is also in agreement with Sang et al. and Wu et al., who explained there are four ranges of $2 \theta ; 7^{\circ}$ to $10^{\circ}, 16^{\circ}$ to $22^{\circ}, 25^{\circ}$ to $30^{\circ}$ and $33^{\circ}$ to $38^{\circ}$ that are assigned as peaks of HPA anions which are depicted as Keggin structure. ${ }^{17,18}$ So, it is confirmed that both synthesized $\mathrm{Cs}_{2.5} \mathrm{H}_{0.5} \mathrm{PW}_{12} \mathrm{O}_{40}$ and $\mathrm{Cs}_{1.87} \mathrm{H}_{1.13} \mathrm{PW}_{12} \mathrm{O}_{40}$ have Keggin structure.

\section{Thermal study by using TGA and DSC}

The thermal analysis of heteropoly acid salts was carried between $25{ }^{\circ} \mathrm{C}$ to $800{ }^{\circ} \mathrm{C}$ [Figure 3(a) and Figure 3(b)]. The thermogram of both Cesium heteropoly acids is depicted in Figure 3(a). In general, Cs 2.50 HPA shows higher thermal stability compared to Cs 1.87 HPA. The first decomposition for Cs $2.50 \mathrm{HPA}$ and Cs $1.87 \mathrm{HPA}$ are shown as endothermic peaks at $70{ }^{\circ} \mathrm{C}$ to $200{ }^{\circ} \mathrm{C}$ and $90{ }^{\circ} \mathrm{C}$ to $160{ }^{\circ} \mathrm{C}$, respectively, which are due to the dehydration of crystalline water. ${ }^{19-20}$ Another endothermic peak is observed in Cs 1.87 HPA between $200{ }^{\circ} \mathrm{C}$ to $320^{\circ} \mathrm{C}$. This endothermic peak can also be detected in thermogram of Cs $2.50 \mathrm{HPA}$. According to Izumi et al., this peak represented another form of dehydration of water molecules in the Keggin structure of Cs HPA. It is suggested that water molecules are possibly combined with $\mathrm{H}^{+}$, forming hydroxonium $\mathrm{H}\left(\mathrm{H}_{2} \mathrm{O}\right)_{n}{ }_{n}^{+}{ }^{+19}$ The third weight loss for Cs $1.87 \mathrm{HPA}$ appeared as exothermic peak at between $536{ }^{\circ} \mathrm{C}$ to $591{ }^{\circ} \mathrm{C}$ in which DSC suggesting the collapse of the Keggin heteropoly anion. ${ }^{21}$

$$
\mathrm{H}_{3} \mathrm{PW}_{12} \mathrm{O}_{40} \rightarrow 1 / 2 \mathrm{P}_{2} \mathrm{O}_{5}+12 \mathrm{WO}_{3}+3 / 2 \mathrm{H}_{2} \mathrm{O}
$$

This exothermic decomposition is similar to the DSC thermogram [Figure 3(b)] of bulk heteropoly acid of tungstophosphoric acid. ${ }^{22}$ DSC thermogram for Cs 2.50 HPA however, does not show any exothermic decomposition indicating a thermal stable structure as compared to Cs $1.87 \mathrm{HPA}$. At temperature between $490^{\circ} \mathrm{C}$ to $800^{\circ} \mathrm{C}$, Cs 2.50 HPA shows a weight loss in TGA thermogram which is not observed in the DSC thermogram. This is probably due to the dehydration of water molecules in the form of $\mathrm{H}_{(}\left(\mathrm{H}_{2} \mathrm{O}\right)_{n}{ }^{+}$, suggesting a strong bonding to $\mathrm{PW}_{12} \mathrm{O}_{40}{ }^{3-}$ and decomposition at high temperature. ${ }^{21}$
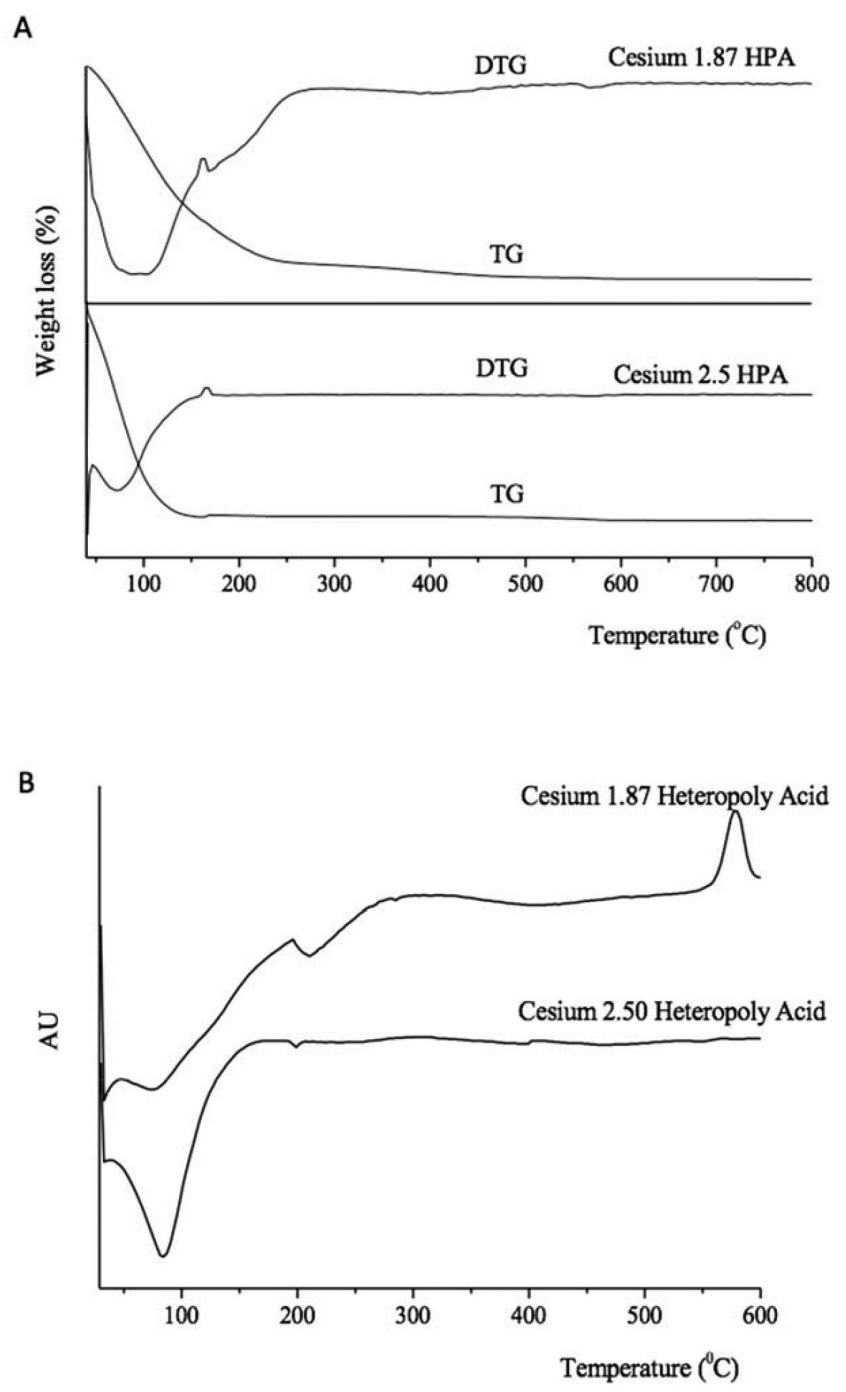

Figure 3. (a) TG and DTG results of Cs 2.50 HPA and Cs $1.87 \mathrm{HPA}$. (b) DSC results of Cs $2.50 \mathrm{HPA}$ and Cs $1.87 \mathrm{HPA}$

\section{Fourier tranmittance infra-red (FTIR)}

FTIR spectra confirmed the structure of the compounds prepared [Figure 4(a) and 4(b)]. Figure 4(b) above shows FTIR spectra from $1216 \mathrm{~cm}^{-1}$ to $402 \mathrm{~cm}^{-1}$. Both of HPA salts show similar bands at $1079 \mathrm{~cm}^{-1}, 986 \mathrm{~cm}^{-1}, 888 \mathrm{~cm}^{-1}, 802 \mathrm{~cm}^{-1}, 594 \mathrm{~cm}^{-1}$ and $522 \mathrm{~cm}^{-1}$. Despite of these similarities, it can be observed that the intensity for Cs $2.50 \mathrm{HPA}$ is higher than Cs $1.87 \mathrm{HPA}$. The first band at $1079 \mathrm{~cm}^{-1}$ is characteristized as asymmetric stretching vibration of $\mathrm{P}-\mathrm{O}$ bond in the central $\mathrm{PO}_{4}$ tetrahedron. ${ }^{15,23,25}$ The band at $986 \mathrm{~cm}^{-1}$ assigned to the stretching vibration of $\mathrm{W}=\mathrm{O}_{\mathrm{t}}$ (terminal oxygen in the Keggin structure). These two bands indicate the presence of the $\mathrm{PW}_{12} \mathrm{O}_{40}{ }^{3-}$ anion after the exchange of protons in the parent acid by $\mathrm{Cs}^{+}$cation. ${ }^{23}$ The third band in this region; $888 \mathrm{~cm}^{-1}$ and $802 \mathrm{~cm}^{-1}$ are due to the stretching vibration of $\mathrm{W}-\mathrm{O}_{\mathrm{b}}-\mathrm{W}$ and $\mathrm{W}-\mathrm{O}_{\mathrm{c}}-\mathrm{W}$, respectively. ${ }^{15,23-25}$ The band for $\delta(\mathrm{O}-\mathrm{P}-\mathrm{O})$ appeared at $594 \mathrm{~cm}^{-1} \cdot{ }^{24,25}$ And the final band in these spectra observed at $522 \mathrm{~cm}^{-1} \mathrm{can}$ be characteristized by the vibration symmetric for W-O-W. ${ }^{15,24,25}$

Temperature-Programmed Desorption (TPD)

Figure 5(a) and 5(b) shows the $\mathrm{NH}_{3}$-TPD profiles for both $\mathrm{Cs}$ 

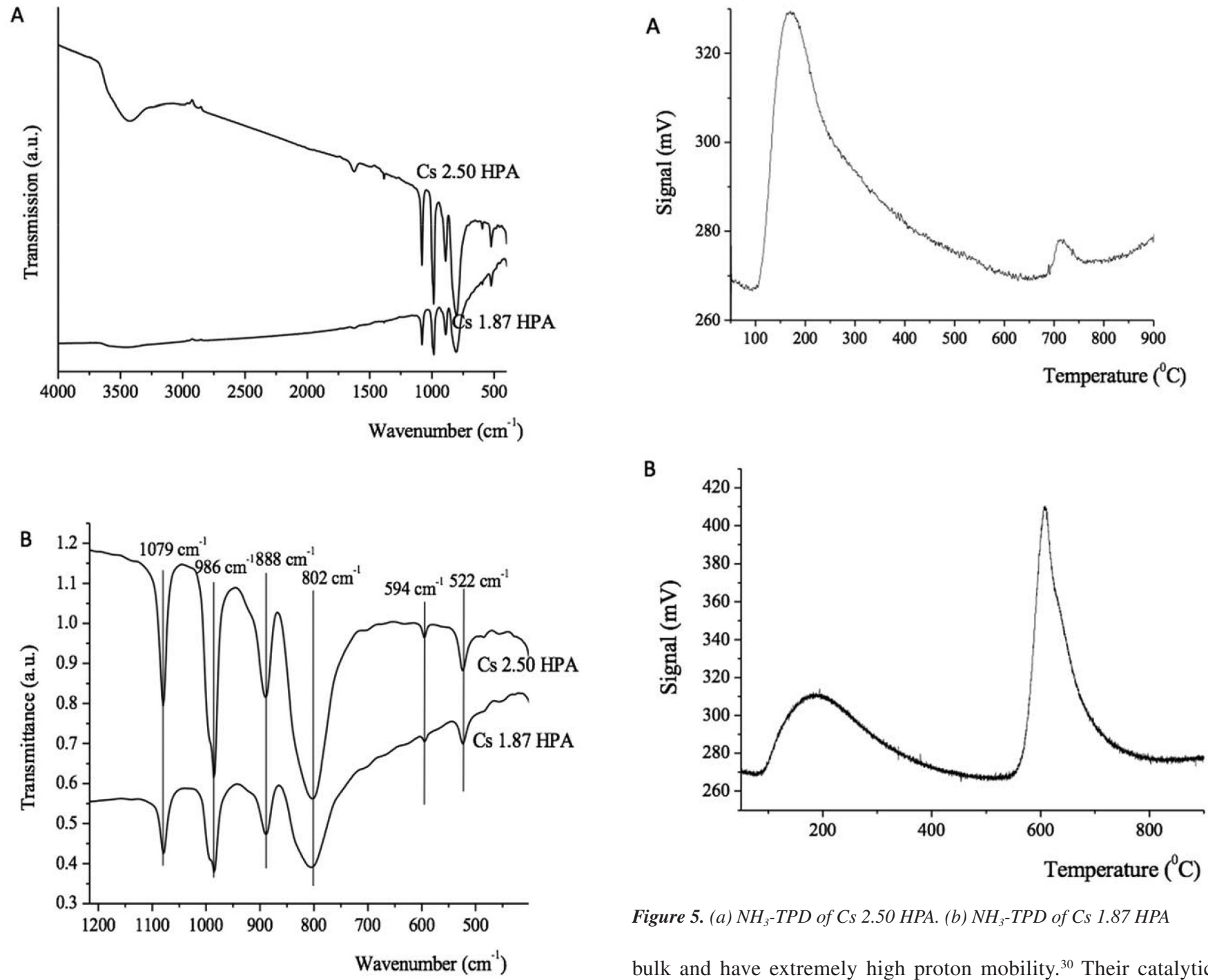

Figure 5. (a) $\mathrm{NH}_{3}$-TPD of Cs 2.50 HPA. (b) $\mathrm{NH}_{3}$-TPD of Cs $1.87 \mathrm{HPA}$

Figure 4. (a) FTIR result for HPA Cs 2.5 and HPA Cs 1.87. (b) FTIR spectra for the region from 1216 to $402 \mathrm{~cm}^{-1}$

HPAs. The $\mathrm{NH}_{3}$ uptake is propotional to the number of acid sites present in the catalyst. ${ }^{26}$ The peak in the high and low temperature area represent of desorption of $\mathrm{NH}_{3}$ from strong and weak acid sites. ${ }^{26,27}$ The peak in the high temperature region can be due to the desorption of strong Bronsted acid site strength. ${ }^{28}$ From the results, there are two peaks; the first appreared in the weak acid region and the second appeared in the strong acid region. Based on the studies done by Tanabe ${ }^{28}$ the acid sites can be categorized into three strength depending on which region the peak appear. The three regions are weak acid strength between $150{ }^{\circ} \mathrm{C}$ to $300^{\circ} \mathrm{C}$, moderate acid strength between $300^{\circ} \mathrm{C}$ to $500{ }^{\circ} \mathrm{C}$ and strong acid strength which cover region that exceed $500{ }^{\circ} \mathrm{C}$. Table 1 shows the estimated acid strength for each catalyst. From the results, it is obvious that Cs 1.87 HPA has significantly more strong acid sites when compare to Cs 2.50 HPA. This is because less $\mathrm{H}^{+}$were substituted in this catalyst. The acid strength of $\mathrm{Cs} 2.50 \mathrm{HPA}$ decreased when more $\mathrm{H}^{+}$were substituted with $\mathrm{Cs}^{2+}$ cations.

\section{Catalytic performances studies}

HPAs in solution as well as in solid state have similar Keggin molecular structure that allow HPA to behave like concentrated solutions. Solid HPAs have the ability to absorb a large amount of polar molecules (such as alcohols, ethers, amine, etc.) in the catalyst

bulk and have extremely high proton mobility. ${ }^{30}$ Their catalytic reactions occur not only on the surface, but also in the bulk of the crystalline HPA. Due to this unique characteristic of the polar solution, solid HPAs behave as a highly concentrated solution as such all HPAs protons, not only the surface proton sites, participate in the catalytic reaction. ${ }^{30-33}$ This phenomenon, which is unusual in heterogeneous acid catalyst, is called as "pseudoliquid phase". $30-33$ The HPAs used in this work were cesium 2.50 heteropoly acid (Cs 2.50 HPA) and cesium 1.87 heteropoly acid (Cs $1.87 \mathrm{HPA}$ ). Yield of PEG-monooleate at $130^{\circ} \mathrm{C}$ and $150^{\circ} \mathrm{C}$ for different mole ratio is presented in the Figure 6. Table 1 and Table 2 are showing the conversion (\%) of oleic acid to product(s) and also the selectivity (\%) of both; PEG-monooleate and PEG-dioleate (by-product).

Before reaction, both type of catalysts were activated at $100{ }^{\circ} \mathrm{C}$ for 2 hours. By doing this, the accessibility to the active site is better leading to the improvement of the catalytic activity. Since the esterification reaction is sensitive to water whereby it can hydrolyse the ester, giving back the starting materials, the catalyst was activated under vacuum. This is to achieve a maximum dehydration of the surface compatible with the stability of the structure.

\section{Effect of mole ratio}

The mole ratio of fatty acid to alcohol is one of the most important factors that influences the conversion and selectivity. Esterification of oleic acid and PEG-600 were conducted in two different mole ratios; 1:1 and 1:4 (oleic acid:PEG-600). Yield (\%) of PEG-monooleate as well as conversion (\%) of oleic acid and 
Table 1. $\mathrm{NH}_{3}$-TPD of Cs heteropoly acid

\begin{tabular}{lcccc}
\hline Catalyst & Desorption Temperature $\left({ }^{\circ} \mathrm{C}\right)$ & Amount gas adsorbed $(\mu \mathrm{mol} / \mathrm{g})$ & Integral $(\mathrm{mVs})$ & Acid strength \\
\hline Cs $1.87 \mathrm{HPA}$ & $189{ }^{\circ} \mathrm{C}$ & 1003.824 & $38,693.65$ & Weak acid strength \\
& $615^{\circ} \mathrm{C}$ & 1652.332 & $57,999.03$ & Strong acid strength \\
\hline $\mathrm{Cs} 2.50 \mathrm{HPA}$ & $168^{\circ} \mathrm{C}$ & 461.813 & $22,102.49$ & Weak acid strength \\
& $723{ }^{\circ} \mathrm{C}$ & 54.758 & $2,620.73$ & Strong acid strength \\
\hline
\end{tabular}
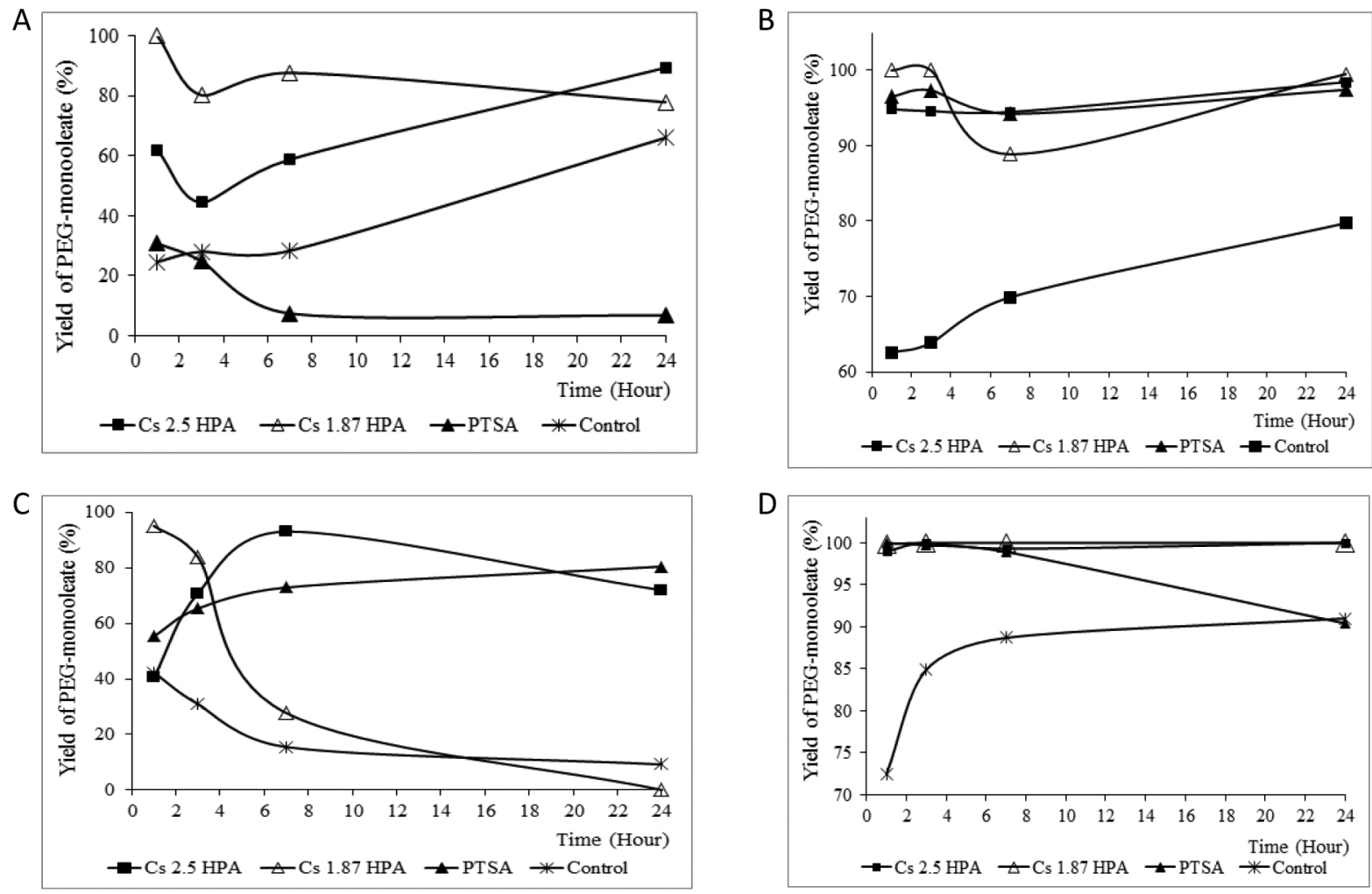

Figure 6. (a) Yield (\%) of PEG-monooleate at $130{ }^{\circ} \mathrm{C}$ for 1:1 mole ratio. (b) Yield (\%) of PEG-monooleate at $130{ }^{\circ} \mathrm{C}$ for $1: 4$ mole ratio. (c) Yield (\%) of PEG-monooleate at $150{ }^{\circ} \mathrm{C}$ for 1:1 mole ratio. (d) Yield (\%) of PEG-monooleate at $150{ }^{\circ} \mathrm{C}$ for $1: 4$ mole ratio

Table 2. Conversion (\%) of oleic acid and selectivity (\%) of PEG-monooleate at 1 and 24 hours for $130{ }^{\circ} \mathrm{C}$

\begin{tabular}{|c|c|c|c|c|c|c|c|c|c|c|c|c|}
\hline \multirow{4}{*}{ Catalyst } & \multicolumn{6}{|c|}{ Mole ratio (oleic acid:PEG-600): 1:1 } & \multicolumn{6}{|c|}{ Mole ratio (oleic acid:PEG-600): 1:4 } \\
\hline & \multirow{3}{*}{$\begin{array}{c}\text { Conv. } \\
(\%)\end{array}$} & \multicolumn{2}{|l|}{1 hour } & \multicolumn{3}{|c|}{24 hours } & \multicolumn{3}{|c|}{1 hour } & \multicolumn{3}{|c|}{24 hours } \\
\hline & & \multicolumn{2}{|c|}{ Selectivity $(\%)$} & \multirow{2}{*}{$\begin{array}{c}\text { Conv. } \\
(\%)\end{array}$} & \multicolumn{2}{|c|}{ Selectivity (\%) } & \multirow{2}{*}{$\begin{array}{c}\text { Conv. } \\
(\%)\end{array}$} & \multicolumn{2}{|c|}{ Selectivity $(\%)$} & \multirow{2}{*}{$\begin{array}{l}\text { Conv. } \\
(\%)\end{array}$} & \multicolumn{2}{|c|}{ Selectivity $(\%)$} \\
\hline & & $\begin{array}{c}\text { PEG- } \\
\text { monooleate }\end{array}$ & $\begin{array}{l}\text { PEG- } \\
\text { dioleate }\end{array}$ & & $\begin{array}{c}\text { PEG- } \\
\text { monooleate }\end{array}$ & $\begin{array}{l}\text { PEG- } \\
\text { dioleate }\end{array}$ & & $\begin{array}{c}\text { PEG- } \\
\text { monooleate }\end{array}$ & $\begin{array}{l}\text { PEG- } \\
\text { dioleate }\end{array}$ & & $\begin{array}{c}\text { PEG- } \\
\text { monooleate }\end{array}$ & $\begin{array}{l}\text { PEG- } \\
\text { dioleate }\end{array}$ \\
\hline Cs $2.50 \mathrm{HPA}$ & 62.0 & 100.0 & 0.0 & 100.0 & 89.6 & 10.4 & 98.8 & 100.0 & 0.0 & 98.4 & 100.0 & 0.0 \\
\hline Cs $1.87 \mathrm{HPA}$ & 100.0 & 100.0 & 0.0 & 78.9 & 98.7 & 1.3 & 100.0 & 100.0 & 0.0 & 100.0 & 100.0 & 0.0 \\
\hline$p$-TSA & 96.0 & 32.1 & 67.9 & 100.0 & 6.8 & 93.2 & 100.0 & 96.9 & 3.1 & 100.0 & 97.6 & 2.4 \\
\hline Control & 24.7 & 100.0 & 0.0 & 71.2 & 92.8 & 7.2 & 62.6 & 100.0 & 0.0 & 79.7 & 100.0 & 0.0 \\
\hline
\end{tabular}

selectivity (\%) of PEG-monooleate at different reaction parameters are shown in Figure 6, Table 2 and Table 3, respectively. As stated earlier, esterification is an equilibrium-limited chemical reaction. Therefore, reactants mole ratio is an important factor in determining the distribution of oleic acid being converted, viz-a-viz, determine the selectivity of product.

From the results above, mole ratio of reactants do play an important role on the selectivity of monoester and its reaction rate. As expected, excess alcohol leads to a favorable condition to help the reaction instead of the stoichiometry reactants ratio, ie. $1: 1 .^{1,4,33}$
The catalytic activity for 1:4 mole ratio occurred very fast at the early reaction. As the mole ratio increased from 1:1 to $1: 4$, the conversion of oleic acid also increased. However, this effect was not observed in Cs 1.87 HPA catalyzed reaction. It seems that, the conversion of oleic acid for this catalyst was not effected by the mole ratio. The conversion for $130{ }^{\circ} \mathrm{C}$ at 1 hour was the same (100.0\%) for both of mole ratios. Similarly, the conversion for $150{ }^{\circ} \mathrm{C}$ at 1 hour was also high with not much different; $98.5 \%$ and $100.0 \%$ respectively.

Mole ratio also effect the selectivity of products. From the reaction results demonstrated in Table 2 and Table 3, no by-product 
Table 3. Conversion (\%) of oleic acid and selectivity (\%) of PEG-monooleate at 1 and 24 hours for $150{ }^{\circ} \mathrm{C}$

\begin{tabular}{|c|c|c|c|c|c|c|c|c|c|c|c|c|}
\hline \multirow{4}{*}{ Catalyst } & \multicolumn{6}{|c|}{ Mole ratio (oleic acid:PEG-600): $1: 1$} & \multicolumn{6}{|c|}{ Mole ratio (oleic acid:PEG-600): 1:4 } \\
\hline & \multicolumn{3}{|c|}{1 hour } & \multicolumn{3}{|c|}{24 hours } & \multicolumn{3}{|c|}{1 hour } & \multicolumn{3}{|c|}{24 hours } \\
\hline & \multirow{2}{*}{$\begin{array}{c}\text { Conv. } \\
(\%)\end{array}$} & \multicolumn{2}{|c|}{ Selectivity (\%) } & \multirow{2}{*}{$\begin{array}{c}\text { Conv. } \\
(\%)\end{array}$} & \multicolumn{2}{|c|}{ Selectivity (\%) } & \multirow{2}{*}{$\begin{array}{c}\text { Conv. } \\
(\%)\end{array}$} & \multicolumn{2}{|c|}{ Selectivity (\%) } & \multirow{2}{*}{$\begin{array}{c}\text { Conv. } \\
(\%)\end{array}$} & \multicolumn{2}{|c|}{ Selectivity (\%) } \\
\hline & & $\begin{array}{c}\text { PEG- } \\
\text { monooleate }\end{array}$ & $\begin{array}{l}\text { PEG- } \\
\text { dioleate }\end{array}$ & & $\begin{array}{c}\text { PEG- } \\
\text { monooleate }\end{array}$ & $\begin{array}{c}\text { PEG- } \\
\text { dioleate }\end{array}$ & & $\begin{array}{c}\text { PEG- } \\
\text { monooleate }\end{array}$ & $\begin{array}{c}\text { PEG- } \\
\text { dioleate }\end{array}$ & & $\begin{array}{c}\text { PEG- } \\
\text { monooleate }\end{array}$ & $\begin{array}{c}\text { PEG- } \\
\text { dioleate }\end{array}$ \\
\hline Cs $2.50 \mathrm{HPA}$ & 40.5 & 100.0 & 0.0 & 100.0 & 72.3 & 27.7 & 99.0 & 100.0 & 0.0 & 100.0 & 100.0 & 0.0 \\
\hline Cs $1.87 \mathrm{HPA}$ & 98.5 & 96.5 & 3.5 & 99.3 & 0.0 & 100.0 & 100.0 & 100.0 & 0.0 & 100.0 & 100.0 & 0.0 \\
\hline$p$-TSA & 100.0 & 42.3 & 57.7 & 100.0 & 9.2 & 90.8 & 100.0 & 100.0 & 0.0 & 95.1 & 95.1 & 4.9 \\
\hline Control & 100.0 & 100.0 & 0.0 & 100.0 & 98.6 & 1.4 & 72.5 & 100.0 & 0.0 & 91.0 & 100.0 & 0.0 \\
\hline
\end{tabular}

(PEG-dioleate) formed when excess PEG-600 was used in the reaction. Contrary to that, PEG-dioleate always formed when stoichiometry mole ratio was used; $1: 1$. This can be seen clearly in the Cs $1.87 \mathrm{HPA}$ catalyzed reaction at $150{ }^{\circ} \mathrm{C}$ where formation of PEG-dioleate reached $100.0 \%$ at 24 hours.

The results for heterogeneous catalyzed reaction is compared with homogeneous catalyst; $p$-TSA. Even though the reaction rate was fast, however in terms of selectivity, $p$-TSA gave poor selectivity compared to that of heterogeneous catalyst. It is demonstrated that there is a drop in selectivity of PEG-monooleate in the presence of $p$-TSA especially in 1:1 mole ratio as compared to that in the presence of heterogeneous solid acid catalysts. This phenomena is more pronounced at the end of reaction time.

\section{Effect of reaction temperature}

Another important factor that affects the catalytic performance is the reaction temperature. Esterification of oleic acid and PEG-600 was carried out at two different temperatures; $130{ }^{\circ} \mathrm{C}$ and $150{ }^{\circ} \mathrm{C}$ (Table 2 and Table 3).

The effect of reaction temperature was different between the two mole ratios. In 1:1 mole ratio, a decrease in conversion of oleic acid was observed at the 1 hour of reaction time. Both heterogeneous catalysts showed reduction in conversion as much as $21.5 \%$ and $1.5 \%$ respectively, when the reaction temperature increased by $20^{\circ} \mathrm{C}$. This effect however was not seen when the reaction progressed to 24 hours. This was totally the opposite for 1:4 mole ratio where the conversion was maintained throughtout the reaction.

The increase in reaction temperature was also accompanied by an increase in the selectivity toward PEG-dioleate rather than PEG-monooleate. When the reaction temperature increases, the reactants become more reactive and less selective at the same time, thus inducing a decrease in the selectivity for of PEG-monooleate. ${ }^{1}$ Due to this factor, the free $\mathrm{OH}$ groups in PEG-monooleate would react further leading to the formation of PEG-dioleate, resulting in an equilibrium mixture of mono- and dioleate. ${ }^{1}$ This behaviour was independent with the type of catalyst. ${ }^{35}$

\section{Effect of reaction time}

The esterification of oleic acid and PEG-600 was carried out for 24 hours (Figure 6, Table 2 and Table 3). Two type of mole ratios studied for comparison; 1:1 and 1:4 (oleic acid:PEG-600) and the catalyst loading was kept at $4 \%$ based on the total amount of reactants. From the results obtained, reaction time effect differently to heterogeneous and homogeneous catalysts. Not only that, it is also effect differently based on the mole ratios of the two reactants.

No significant changes took place in the heterogeneous catalyzed esterification with 1:4 mole ratio. Both catalysts; Cs $2.50 \mathrm{HPA}$ and Cs 1.87 HPA maintaning high conversion and selectivity through out the reaction. Already at the early stage, the conversion almost completed for Cs 2.50 HPA and totally completed for Cs 1.87 HPA. The selectivity of PEG-monooleate also remained high through out the reaction; no formation PEG-dioleate.

Prolong reaction time however does not gave a good outcome for $p$-TSA. It can be seen, the conversion of oleic acid didn't influenced by reaction time at $130{ }^{\circ} \mathrm{C}$ reactions. On the other hand, for $150{ }^{\circ} \mathrm{C}$ reactions, the conversion dropped as much as $4.9 \%$ when proceed to 24 hours. Selectivity was not fully toward PEG-monooleate when reaction extended to 24 hours. PEG-dioleate formed during the reaction especially in $150{ }^{\circ} \mathrm{C}$ where it reached $4.9 \%$ after 24 hours.

Control reactions having the slowest catalytic activity among all. Even though the reaction reaction was far from complete, the conversion was gradually increased when the reaction was allowed to proceed longer. In both temperatures, conversion increased as much as $17.1 \%$ and $18.5 \%$, respectively, after 24 hours. Unlike the homogeneous catalyzed reactions, selectivity toward PEGmonooleate sustained at $100 \%$ all through out reactions.

The outcome of reaction time was significant for the 1:1 mole ratio reactions especially in the aspect of selectivity. For heterogeneous catalysts (Cs 2.50 HPA and Cs 1.87 HPA), conversion increased when the reaction reached 24 hours except for reaction that was catalyzed using Cs $1.87 \mathrm{HPA}$ at $130{ }^{\circ} \mathrm{C}$ where there was significant drop as much as $21.1 \%$. However, lengthen the reaction time until 24 hours didn't give a positive effect on the selectivity of PEG-monooleate. Drop in the selectivity of PEG-monooleate occurred greatly; the effect was obvious especially for the reaction catalyzed by Cs 1.87 HPA at $150{ }^{\circ} \mathrm{C}$, where no formation of PEG-monoleate detected at 24 hours.

Effect of reaction time for homogeneous catalyst ( $p$-TSA) was similar to heterogeneous catalysts. The conversion increased parallel with reaction time and the selecitivity of PEG-monooleate dropped when the reaction was allowed to proceed until 24 hours. There only different was that, unlike the heterogeneous catalyzed reactions, the formation of PEG-dioleate was already in significant amount even at the early stage of reaction. This can be seen clearly in both reaction temperatures where at 1 hour of reaction, PEG-dioleate formed as much as $67.9 \%$ and $57.7 \%$, respectively.

Reaction time effected differently in both reaction temperature. The catalytic activity started very slow at $130{ }^{\circ} \mathrm{C}$ compare to reaction at $150{ }^{\circ} \mathrm{C}$ where the reaction was already completed; which can be translated by $100 \%$ conversion of oleic acid. While conversion for $150{ }^{\circ} \mathrm{C}$ remained high, the conversion for $130{ }^{\circ} \mathrm{C}$ gradually increased to $71.2 \%$ when the reaction stopped. $100 \%$ selectivity of PEG-monooleate achieved at the early reaction. However, when the reaction proceed to 24 hours, PEG-dioleate formed as much as $7.2 \%$ and $1.4 \%$, respectively.

\section{Effect of acidity of catalyst}

The acidity of catalysts tested do effect on the catalytic performance. From the results above, the conversion of oleic acid in 
Cs 1.87 HPA catalyzed reaction at the initial reaction is much better than those reaction that catalyzed by Cs 2.50 HPA. This especially happened in the 1:1 mole ratio reaction.

In terms of selectivity, Cs $2.50 \mathrm{HPA}$ give better selectivity to PEG-monooleate compared to Cs $1.87 \mathrm{HPA}$. For example, at $150{ }^{\circ} \mathrm{C}$ with $1: 1$ mole ratio at 24 hours, Cs 1.87 HPA give $100.0 \%$ selectivity to PEG-dioleate compared to only $27.7 \%$ of selectivity given by $\mathrm{Cs}$ $2.5 \mathrm{HPA}$. This can be explained with number of $\mathrm{Cs}^{+}$ion in both HPA Cs tested. Cs 1.87 HPA has less number of $\mathrm{Cs}^{+}$ion. This means that the number of $\mathrm{H}^{+}$in $\mathrm{Cs} 1.87 \mathrm{HPA}$ is more compared to Cs $2.50 \mathrm{HPA}$, making it more reactive. The PEG-monooleate formed during the reaction was likely undergo another cycle of reaction producing PEG-dioleate.

When compare with $p$-TSA, it can be observed that homogeneous catalyst more likely producing PEG-dioleate. The reaction rate is very rapid with high conversion to products since early stage of reaction. However, selectivity of PEG-monooleate obtained is very poor. This clearly be seen in the $1: 1$ mole ratio at $150{ }^{\circ} \mathrm{C}$ where selectivity to PEG-dioleate is much higher; $57.7 \%$ at the initial stage of reaction to $90.8 \%$ when the reaction stopped.

\section{CONCLUSION}

It has been shown that heterogeneous acid catalysts; Cs HPAs are active and selective catalyst for the synthesis of PEG-monooleate. In this reaction, it was shown that the preferable mole ratio between oleic acid and PEG-600 was 1:4. In this mole ratio, the selectivity toward the PEG-monooleate was maintained at $100 \%$ with no formation of by-product; PEG-dioleate. Reactans mole ratio not only plays an important role for selectivity, it also has an effect on the reaction rate/ conversion. It was demonstrated that the rate of reaction was very rapid and reaching into completion at the very initial stage.

Second parameter investigated in this work was reaction temperature. It can be concluded that in the temperature range studied, i.e. $130{ }^{\circ} \mathrm{C}$ to $150{ }^{\circ} \mathrm{C}$, the $20^{\circ} \mathrm{C}$ difference in reaction temperature doesn't really have any significant effect on the selectivity and reaction rate/conversion for the 1:4 mole ratio. However, for the 1:1 mole ratio, the opposite correlation between temperature and selectivity of PEG-monooleate was observed. Higher reaction temperature is favorable for the formation of PEG-dioleate. This became obvious especially for Cs 1.87 HPA catalyzed reaction at 24 hours. From this study, it is also can be concluded that reaction time has the same effect as the reaction temperature. All in all, the most important parameter is mole ratio between the reactant and co-reactant which give the most significant effect on the catalytic activity in term of conversion of oleic acid, selectivity of PEG-monooleate and yield of product(s). The last parameter investigated was the effect of acidity to the catalytic activity. The effect of acidity has no significant influence for 1:4 mole ratio. However the effect of acidity can be clearly seen in 1:1 mole ratio reactions. Poor selectivity of PEG-monooleate was given by $\mathrm{Cs}$ $1.87 \mathrm{HPA}$ in $1: 1$ mole ratio, especially for the reaction at $150{ }^{\circ} \mathrm{C}$ at 24 hours compare to Cs 2.50 HPA which only $27.7 \%$.

\section{SUPPLEMENTARY MATERIAL}

HPLC results are available at http://quimicanova.sbq.org.br, in the form of PDF file, with free access.

\section{ACKNOWLEDGEMENT}

Financial support from NANOCAT (Universiti Malaya), Ministry of Science, Technology and Innovation (MOSTI), research grant: IRPA RM8 09-02-03-3012 SR0004/05-02 (Development of catalyst for the synthesis of oleochemicals derived biodegradable surfactants) and also the technical support from Instituto de Tecnología Química (ITQ), Spain are gratefully acknowledged.

\section{REFERENCE}

1. Abd Hamid, S. B.; Abdullah, F. Z.; Ariyanchira, S.; Mifsud, M.; Iborra, S.; Corma, A.; Catal. Today 2004, 97, 271.

2. Leong, W. F.; Man, Y. B. C.; Lai, O. M.; Long, M.; Nakajima, M.; Tan, C. P.; J. Food. Eng. 2011, 104, 63.

3. Fruijtier-Pölloth, C.; Toxicology 2005, 214, 1.

4. Marchetti, J. M.; Errazu, A. F.; Biomass Bioenergy 2008, 32, 892.

5. Fernandes, S. A.; Natalino, R.; Silva, M. J. D.; Lima, C. F.; Catal. Commun. 2012, 26, 127.

6. Rönnback, R.; Salmi, T.; Vuori, A.; Haario, H.; Lehtonan, J.; Sundqvist, A.; Tirronen, E.; Chem. Eng. Sci. 1997, 52, 3369.

7. Borges, M. E.; Díaz, L.; Renewable Sustainable Energy Rev. 2012, 16, 2839.

8. Lam, M. K.; Lee, K. T.; Mohamed, A. R.; Biotechnol. Adv. 2010, 28, 500.

9. Helwani, Z.; Othman, M. R.; Aziz, N.; Kim, J.; Fernando, W. J. N.; Appl. Catal., A 2009, 363, 1.

10. Rufino, A.R.; Biaggio, F. C.; Santos, J. C.; Castro, H. F. D.; Int. J. Biol. Macromol. 2010, 47, 5 .

11. Rahman, M. B. A.; Jumbri, K.; Hanafiah, N. A.M. A.; Abdulmalek, E.; Tejo, B. A.; Basri, M.; Salleh, A. B.; J. Mol. Catal. B: Enzym. 2012, 79, 61.

12. Hasegawa, S.; Azuma, M.; Takahashi, K.; Enzyme Microb. Technol. 2008, 43, 309.

13. Bajaj, A.; Lohan, P.; Jha, P. N.; Mehrotra, R.; J. Mol. Catal. B: Enzym. 2010, 62, 9 .

14. Alsalme, A.; Kozhevnikov, E. F.; Kozhevnikov, I. V.; Appl. Catal., A 2008, 349, 170.

15. Benaissa, H.; Davey, P. N.; Khimyak, Y. Z.; Kozhenikov, I. V.; J. Catal. 2008, 253, 244 .

16. Mizuno, N.; Tateishi, M.; Iwamoto, M.; J. Catal. 1996, 163, 87.

17. Sang, X.; Wu, Q.; Mater. Res. Bull. 2004, 39, 2329.

18. Wu, Q.; Sang, X.; Shao, F.; Pang, W.; Mater. Chem. Phys. 2005, 92, 16.

19. Izumi, Y.; Ogawa, M.; Urabe, K.; Appl. Catal., A 1995, 132, 127.

20. Newman, A. D.; Brown, D. R.; Siril, P.; Lee, A. F.; Wilson, K.; Phys. Chem. Chem. Phys. 2006, 8, 2893.

21. Xian-e, C.; Daichun, D.; Jianping, N.; Youming, J.; Jing, Z.; Yixiang, Q.; Thermochim. Acta 1997, 292, 45.

22. Choi, S.; Wang, Y.; Nie, Z.; Liu, J.; Peden, C. H. F.; Catal. Today 2000 , $55,117$.

23. Corma, A.; Martínez, A.; Martínez, C.; J. Catal. 1996, 164, 422.

24. Essayem, N.; Holmqvist, A.; Gayraud, P. Y.; Vedrine, J. C.; Taarit, Y. B.; J. Catal. 2001, 197, 273.

25. Shin, H. Y.; An, S. H.; Sheikh, R.; Park, Y. H.; Bae, S. Y.; Fuel 2012, 96, 572.

26. Newman, A. D.; Brown, D. R.; Siril, P.; Lee, A. F.; Wilson, K.; Phys. Chem. Chem. Phys. 2006, 8, 2893.

27. Chen, Y.; Cao, Y.; Suo, Y.; Zheng, G. P.; Guan, X. X.; Zheng, X. C.; J. Taiwan Inst. Chem. Eng. 2015, 51, 186.

28. Tanabe, K., Determination of acidic properties on solid surfaces, Solid Acids and Bases, Academic Press, 1970, Chap. 2.

29. Kozhevnikov, I. V.; Chem. Rev. 1998, 98, 171.

30. Timofeeva, M. N., Appl. Catal., A 2003, 256, 19.

31. Corma, A.; Curr. Opin. Solid State Mater. Sci. 1997, 2, 63.

32. Misono, M.; Chem. Commun. 2001, 1141.

33. Kozhevnikov, I. V.; Catal. Rev.: Sci. Eng. 1995, 37, 311.

34. Marchetti, J. M.; Errazu, A. F.; Fuel 2008, 87, 3477.

35. Özbay, N.; Oktar, N.; Tapan, N. A.; Fuel 2008, 87, 1789. 